\title{
Recommendations for a Static Cosmic Ray Shield for Enriched Germanium Detectors
}

\author{
E Aguayo AS Ankney ${ }^{1}$ \\ JL Orrell TJ Berguson ${ }^{1}$
}

September 2011

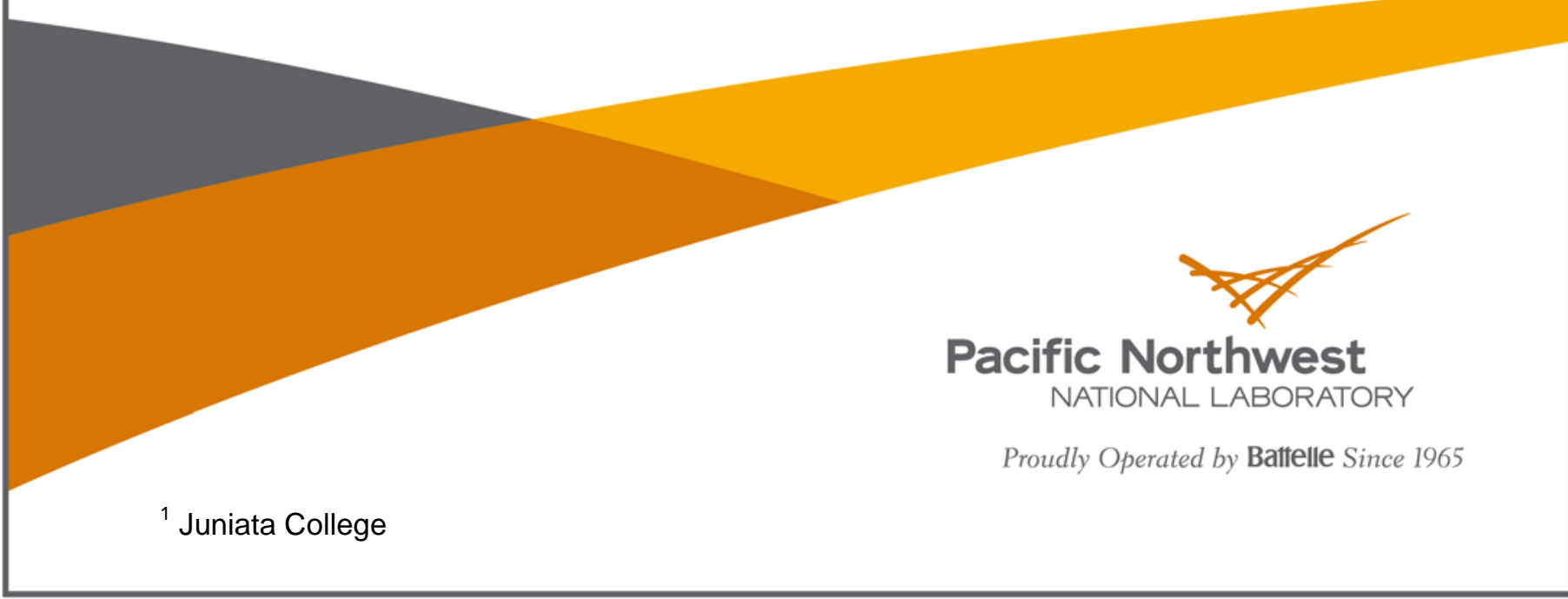




\title{
DISCLAIMER
}

This report was prepared as an account of work sponsored by an agency of the United States Government. Neither the United States Government nor any agency thereof, nor Battelle Memorial Institute, nor any of their employees, makes any warranty, express or implied, or assumes any legal liability or responsibility for the accuracy, completeness, or usefulness of any information, apparatus, product, or process disclosed, or represents that its use would not infringe privately owned rights. Reference herein to any specific commercial product, process, or service by trade name, trademark, manufacturer, or otherwise does not necessarily constitute or imply its endorsement, recommendation, or favoring by the United States Government or any agency thereof, or Battelle Memorial Institute. The views and opinions of authors expressed herein do not necessarily state or reflect those of the United States Government or any agency thereof.

\author{
PACIFIC NORTHWEST NATIONAL LABORATORY \\ operated by \\ BATTELLE \\ for the \\ UNITED STATES DEPARTMENT OF ENERGY \\ under Contract DE-AC05-76RL01830
}

Printed in the United States of America

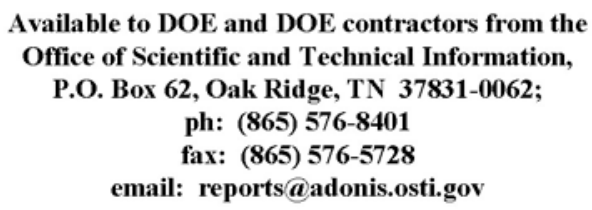

Available to the public from the National Technical Information Service 5301 Shawnee Rd., Alexandria, VA 22312 ph: (800) 553-NTIS (6847) email: orders@ntis.gov $<$ http://www.ntis.gov/about/form.aspx > Online ordering: http://www.ntis.gov 


\title{
Recommendations for a Static Cosmic Ray Shield for Enriched Germanium Detectors
}

\author{
E Aguayo TJ Berguson ${ }^{1}$ \\ AS Ankney ${ }^{1}$ JL Orrell
}

September 2011

Prepared for

the U.S. Department of Energy under Contract DE-AC05-76RL01830

Pacific Northwest National Laboratory

Richland, Washington 99352

${ }^{1}$ Juniata College 

PNNL-20740

\section{Summary}

This document provides a detailed study of cost and materials that could be used to shield the detector material of the international Tonne-scale germanium neutrinoless double-beta decay experiment from hadronic particles from cosmic ray showers at the Earth's surface. This work was motivated by the need for a shield that minimizes activation of the enriched germanium during storage; in particular, when the detector material is being worked on at the detector manufacturer's facility. This work considers two options for shielding the detector material from cosmic ray particles. One option is to use a pre-existing structure already located near the detector manufacturer, such as Canberra Industries in Meriden, Connecticut. The other option is to build a shield onsite at a detector manufacturer's site. This paper presents a cost and efficiency analysis of such construction. 
PNNL-20740

\section{Acronyms and Abbreviations}

\author{
$0 v \beta \beta$ \\ Geant4 \\ HPGe \\ MJD \\ PNNL \\ PE
}

\author{
Neutrinoless double beta decay \\ Geometry and Transport 4 \\ High-purity germanium \\ MAJORANA DEMONSTRATOR \\ Pacific Northwest National Laboratory \\ Polyethylene
}


PNNL-20740

\section{Contents}

1.0

2.0

3.0

4.0

5.0
Introduction........................................................................................................1

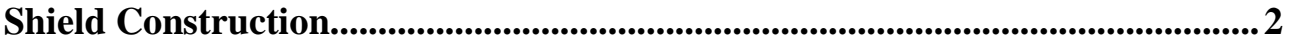

Pre-Fabricated/Pre-Existing Structures ........................................................... 3

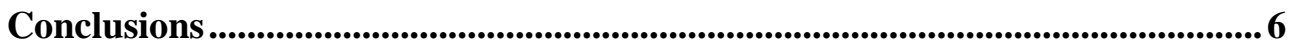

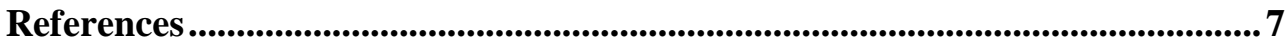

\section{Figures}

Figure 1: Satellite image of what appears to be a large water tank (bottom left), possibly belonging to High Hill Orchards. Note the building/barn in the top right to give a sense of scale.

Figure 2: Satellite image of Suzio York Hill quarry. The quarry is likely $120-210 \mathrm{~m}$ of traprock...5

Figure 3: Satellite image of Canberra Industries showing Bishops Pond (yellow) and the parking lot (red). .6

\section{Tables}

Table 1: Isotopic Composition of ${ }^{76}$ Ge-enriched detector material (Kouzes et al. 2011) .................1

Table 2: This table shows the five different shielding materials. The prices are based on of

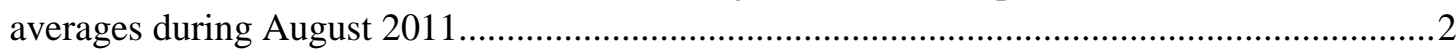

Table 3: Outgoing Neutron Rates for the different materials considered in this study. The cosmic neutron flux for $20 \mathrm{MeV}$ to $10 \mathrm{GeV}$ is 69.89 counts $/ \mathrm{sec} / \mathrm{m}^{2}$.

Table 4: Equivalent thickness for shields of iron (best option) and water (cheapest option)..... 3 


\subsection{Introduction}

The search for neutrinoless double beta decay $(0 v \beta \beta)$ is of fundamental importance for physics (Elliott and Vogel 2002). Pacific Northwest National Laboratory (PNNL) is part of a collaboration conducting experiments that exploit the process of $0 v \beta \beta$ using germanium highly-enriched in ${ }^{76} \mathrm{Ge}$ in highly-purity germanium (HPGe) detectors as a source and detection material in detectors. An ultra lowbackground cryostat will hold the HPGe detectors. Critical to the success of the experiment is the ability to account for and limit all sources of background, to such an extent that this experiment is "all about the backgrounds" (Elliott 2011). The background budget of such a sensitive experiment must account for the amount of all potential sources of background, including those due to cosmic ray activation of the detector material. The specific composition of the enriched detector material is given in Table 1 .

This experiment will be performed deep underground to shield against muons; however, during manufacture and transport, the detector material will be above ground, exposed to the hadronic component of cosmic ray showers. While the material is above ground it will be partially shielded from cosmogenic bombardment using material optimized to reduce the rate of neutron activation (AguayoNavarrete et al. 2011). This document provides calculations to evaluate different shield options for the enriched germanium material while it is stored at the detector manufacturer facility.

In the calculations made in this document, the neutron flux is computed for those neutrons with energy above $20 \mathrm{MeV}$. The reason we focus on this energy range is that the activation energy of the reactions of interest are all above $20 \mathrm{MeV}$ - for example, the activation energy for the reaction ${ }^{70} \mathrm{Ge}$ $(\mathrm{n}, 3 \mathrm{n}){ }^{68} \mathrm{Ge}$.

The purpose of this study is to discover the most effective use of resources in order to obtain the most effective shielding. Many factors are taken into consideration in making this decision, including proximity to the manufacturer, security, cost, time/readiness, shielding efficiency, and shielding materials.

Table 1: Isotopic Composition of ${ }^{76}$ Ge-enriched detector material (Kouzes et al. 2011)

\begin{tabular}{cc}
\hline Isotope & Fractional Composition \\
\hline${ }^{70} \mathrm{Ge}$ & 0.006 \\
${ }^{72} \mathrm{Ge}$ & 0.011 \\
${ }^{73} \mathrm{Ge}$ & 0.033 \\
${ }^{74} \mathrm{Ge}$ & 0.086 \\
${ }^{76} \mathrm{Ge}$ & 0.914 \\
\hline
\end{tabular}




\subsection{Shield Construction}

A static shield would consist of enough material to significantly decrease the exposure to cosmic ray particles. Previous work has shown that neutrons of $20 \mathrm{MeV}$ or more can produce ${ }^{68} \mathrm{Ge}$ and ${ }^{60} \mathrm{Co}$ from natural and enriched germanium (Avignone et al. 1992). All data presented in this section is based on shielding neutrons of those higher energies. The common materials that can shield against high-energy neutrons are iron, lead, concrete, polyethylene (PE), and water (Aguayo et al., 2011). Table 2 shows these materials and information about them relevant to our choice of shield. This table includes an estimated cost per kilogram in order to shows how cost-efficient each material is when shielding against cosmic activation.

Table 2: Five different shielding materials considered. The prices are based on of averages during August 2011.

\begin{tabular}{|c|c|c|c|c|}
\hline \multirow[b]{2}{*}{ Material } & \multicolumn{4}{|c|}{ Static Shield Specs } \\
\hline & Price (per kg) & Density $\left(\mathrm{g} / \mathrm{cm}^{3}\right)$ & Cost (per $\left.\mathrm{m}^{3}\right)$ & Mass $\left(\mathrm{kg}\right.$ per $\left.\mathrm{m}^{3}\right)$ \\
\hline Iron & $\$ 0.33$ & 7.87 & $\$ 2,597.10$ & 7870 \\
\hline Lead & $\$ 2.73$ & 11.34 & $\$ 30,958.20$ & 11340 \\
\hline Concrete & $\$ 0.07$ & 2.32 & $\$ 161.00$ & 2300 \\
\hline Water & $<\$ 0.01$ & 1 & price of tank & 1000 \\
\hline PE & $\$ 0.55$ & 0.95 & $\$ 522.50$ & 950 \\
\hline
\end{tabular}

As Table 2 illustrates, lead is simply too expensive to be considered cost effective; thus, it is immediately rejected. Although concrete is not the most effective material at shielding neutrons, it is the most cost effective of the materials considered — until one adds in the labor that concrete requires, which would add to the final cost of the shield. While iron is cheaper per kilogram than PE, and better at shielding neutrons, PE is a more cost-effective per unit volume. Iron has a mass of $7870 \mathrm{~kg} / \mathrm{m}^{3}$ whereas PE only has a mass of $950 \mathrm{~kg} / \mathrm{m}^{3}$. 
Table 3: Outgoing Neutron Rates for the different materials considered in this study. The cosmic neutron flux for $20 \mathrm{MeV}$ to $10 \mathrm{GeV}$ is 69.89 counts $/ \mathrm{sec} / \mathrm{m}^{2}$.

\begin{tabular}{cccc}
\hline Material & $\begin{array}{c}1 \text { meter } \\
\text { (counts/sec/m2) }\end{array}$ & $\begin{array}{c}2 \text { meter } \\
\text { (counts/sec/m2) }\end{array}$ & $\begin{array}{c}3 \text { meter } \\
\text { (counts/sec/m2) }\end{array}$ \\
\hline Iron & 0.75 & 0.0081 & 0.000088 \\
Lead & 6.4 & insignificant & insignificant \\
Concrete & 20.8 & 6.2 & 1.8 \\
Water & 20.4 & 5.9 & 1.7 \\
PE & 21.1 & 6.4 & 1.9 \\
\hline
\end{tabular}

Table 3 shows the attenuation of high-energy ( $>20 \mathrm{MeV}$ ) cosmic ray neutrons through three thicknesses of shielding material. For any given thickness, lead and iron are clearly the best shield materials. Table 4 shows the thicknesses of water and iron needed to achieve equivalent reductions in the neutron flux, indicating the large thickness of water required as a shield.

Table 4: Equivalent thickness for shields of iron (best shield) and water (cheapest shield)

\begin{tabular}{lccc}
\hline Material & \multicolumn{3}{c}{ Equivalent thickness $(\mathrm{m})$} \\
\hline Iron & 1 & 2 & 3 \\
Water & 4 & 10 & 30 \\
\hline
\end{tabular}

\subsection{Pre-Fabricated/Pre-Existing Structures}

One approach used in this study was to look at options associated with one specific vendor as an example of what might be done to shield the enriched germanium material while at the detector manufacturer. Canberra, located in Meriden, CT, was used as an example of a detector vendor for this study. Roald Haestad, Inc. in Waterbury, Connecticut (less than 30 minutes from Meriden), specializes in the manufacture of water tanks, which are a potential resource for shielding the enriched HPGe detectors during and after contact deposition at Canberra Industries. Storing the detector material under a water 
tank could provide the most efficient shielding, but if purchase of the tank were required, this would be the most expensive option. Purchase should only be considered if there were sufficient long-term applications for the tank. In the short term, rental of space under a tank would be more economical. Other potential candidate structures similar to Roald Haestad's tanks are seen in satellite images of the surrounding area (see Figure 1).

Roald Haestad's tanks range in size from 5 to $33 \mathrm{~m}$ high. In general, water tanks are wider than they are tall, but the focus of the shield should be the vertical cosmic rays. For storage, we would want to optimize the vertical shielding. If purchase were deemed the only viable option, the most advantageous use of the funds allotted to this portion of the work would be to construct a custom tank whose vertical dimension is larger than its horizontal one. A purchased tank could potentially be filled with higher density material.

In the satellite images, there appears to be a water tank already in place just southeast of the Canberra facilities (approximately a five minute drive) which is not owned by Canberra or Roald Haestad. Based on the scale of the satellite image, this tank has a diameter of approximately $33 \mathrm{~m}$, and stands around $8.7 \mathrm{~m}$ tall. By extrapolating from the water shielding simulations, the exposure of neutrons (20 MeV - $10 \mathrm{GeV}$ ) would be reduced enough that the time above ground under this shield could be increased from 100 days (unprotected above ground) to over 9000 years with this much shielding, using current ${ }^{68} \mathrm{Ge}$ production cross section estimates.

Another shielding option is utilizing the Suzio York Hill quarry at Chauncey Peak (approximately an 11 minute drive from Canberra), as seen in Figure 2. Chauncey Peak is composed of $210 \mathrm{~m}$ of rock (2 to 3 times denser than water). It does not appear that the quarry has any underground tunnels already dug, so if this location were to be used as a shielding option, excavation of a tunnel would be another cost and time consideration. A further consideration is the ongoing quarrying, which could pose a risk for the germanium material. The quarry also has two small bodies of water in it; since they do not appear very deep, they are unlikely storage options.

Two potential shielding options exist right on the manufacturer's properties. The first is the possibility that the germanium could be put in Bishops Pond. The two potential drawbacks tothis option are that 1) this might raise health and environmental concerns from different groups; and 2) this option may raise security concerns as well; or conversely, its proximity to the manufacturer's facility may make security a little easier. The other onsite shielding option is using the parking lot seen in Figure 3 to place a rental tank full of water or other shielding material. However, this would occupy many parking spaces, which may require a rental fee as well.

Since most of the rental tanks tend to be wider than they are high, shielding vertical cosmic rays may be a concern, since the cosmic neutron flux at sea level is maximum in the azimuthal angle. One example tank from Adler Tank Rentals has approximate dimensions of $13 \times 2.5 \times 3(\mathrm{l} \times \mathrm{w} \times \mathrm{h})$ meters, and would cost about $\$ 2000$ to use for a month ( $\sim 40 /$ day, plus $\sim \$ 800$ drop off/pick up fee). A 3-m water shield would allow for about 10 years of exposure. Another storage option with the rental tank is placing it by the side of a cliff (such as the cliffs by the quarry or Craig's Castle) so that the majority of nonvertical cosmic rays could be shielded by one side. The tank could also be flipped so that the longest side shields the vertical cosmic rays, although the tank would need to be designed for such orientation. 
PNNL-20740

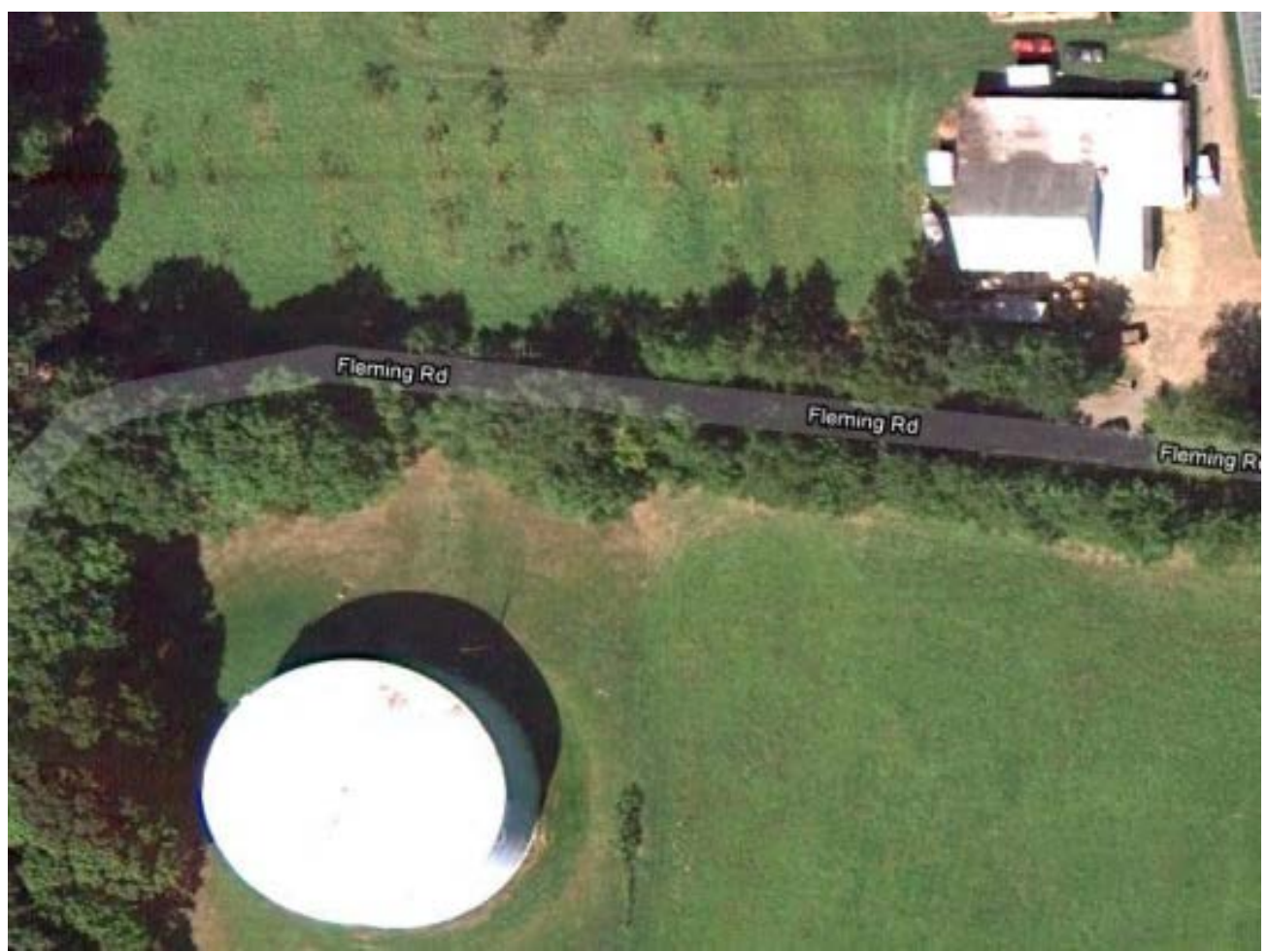

Figure 1: Satellite image of what appears to be a large water tank (bottom left), possibly belonging to High Hill Orchards. Note the building in the top right that provides a sense of scale.

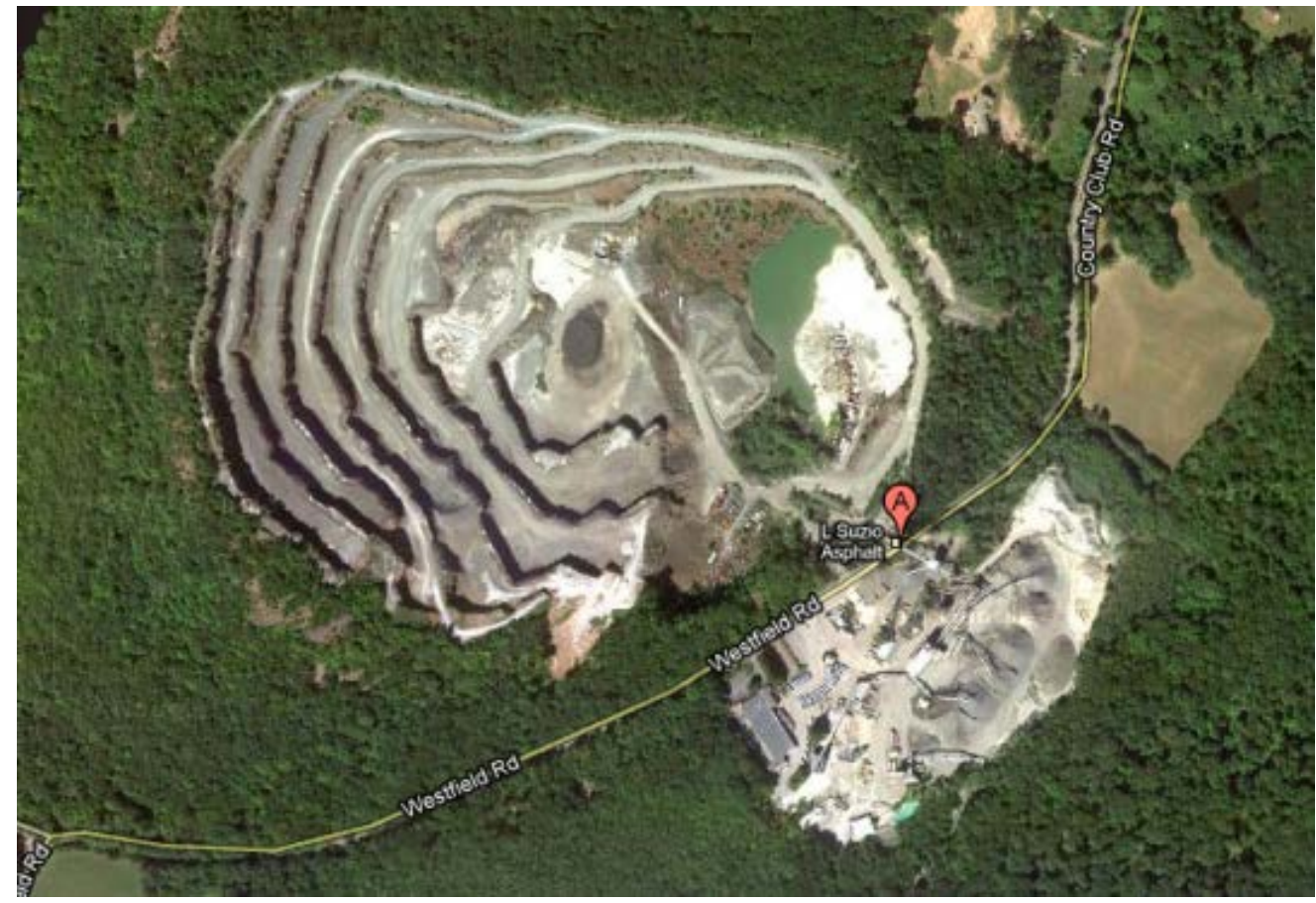

Figure 2: Satellite image of Suzio York Hill quarry. The quarry is likely $120-210 \mathrm{~m}$ of traprock. 
PNNL-20740

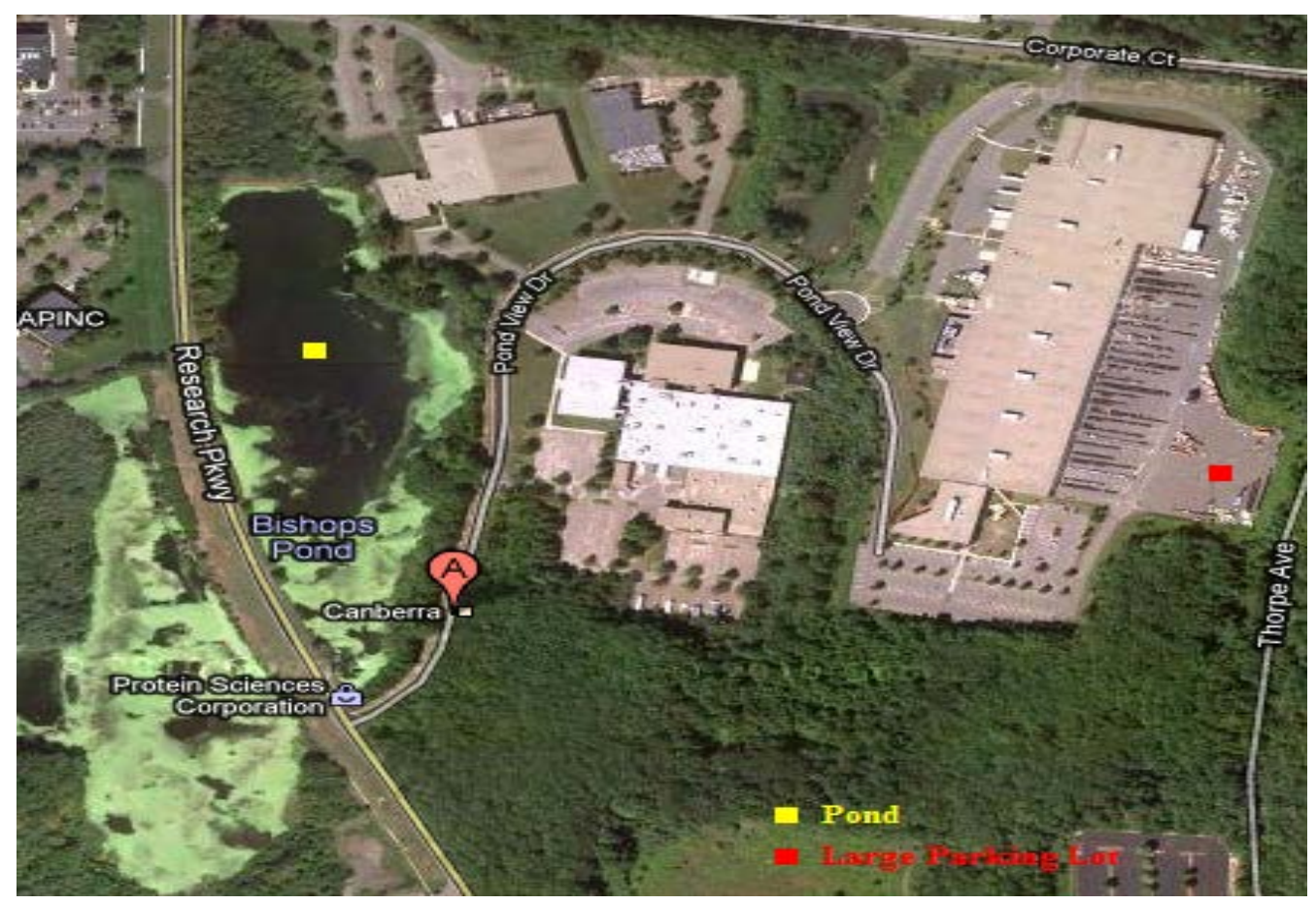

Figure 3: Satellite image of Canberra Industries showing Bishops Pond (yellow) and the parking lot (red)

\subsection{Conclusions}

This report presents an analysis of the options for shielding germanium against cosmogenic production near an HPGe detector manufacturer, exemplified by Canberra Industries in Meriden, CT. While the cheapest option is to use an existing pond or water tower, the shielding provided by water is limited compared to other materials. The next cheapest option would be constructing a shield out of concrete, but it also has limited shielding potential. This could be done either by designing and laying a concrete shield, which would include the price for concrete plus labor, or by buying slabs of precast concrete and placing those over a cavity containing the germanium detectors. Building an iron structure would be expensive, but would provide a better shield. A well near by the detector production facility is also an option. The depth of such well should be matched to the expected time of storage of the enriched material, so the cosmogenic activation rate falls within acceptable levels. 
PNNL-20740

\subsection{References}

Aguayo-Navarrete, E, AS Ankney, TJ Berguson, RT Kouzes, JL Orrell, and MD Troy. 2011. Cosmic Ray Interactions in Shielding Materials. Report No. PNNL-20693, Pacific Northwest National Laboratory, Richland, Washington.

Elliott, SR. 2011. "Double Beta Decay Science and Context." Presentation from MJD Annual Review Meeting, 31 Slides. Majorana Collaboration, Washington, DC.

Elliott, SR, and P Vogel. 2002. "Double Beta Decay." Annual Review of Nuclear and Particle Science 52:115-51. 10.1146/annurev.nucl.52.050102.090641.

Kouzes, RT, M Engelhard, and Z Zhu. 2011. Germanium-76 Sample Analysis Rev 2. Report No. PNNL20368, Pacific Northwest National Laboratory, Richland, Washington. 


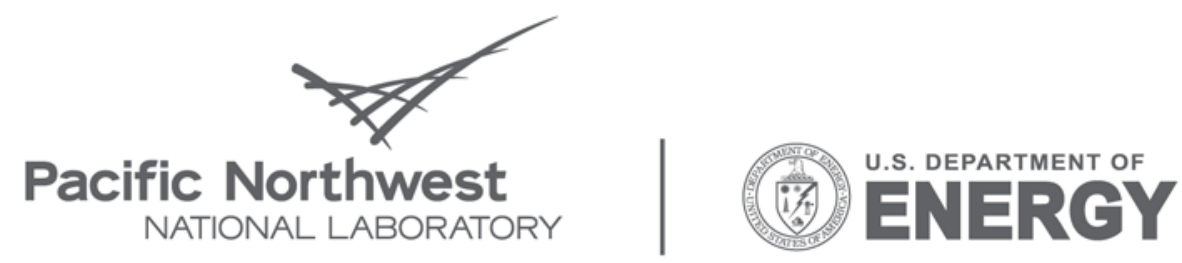

Proudly Operated by Battelle Since 1965

902 Battelle Boulevard

P.O. Box 999

Richland, WA 99352

1-888-375-PNNL (7665)

www.pnl.gov 